\title{
La memoria en directo: La hija del general, novela inédita de Maslow
}

\author{
Berit Balzer HaUs \\ Universidad Complutense de Madrid \\ Departamento de Filología Alemana \\ balzerbe@filol.ucm.es
}

\begin{abstract}
RESUMEN
Arkadij Maslow (1891-1941), político comunista de la República de Weimar y exiliado desde 1933 en París, terminó en 1935 una novela testimonial sobre la llegada de Hitler al poder, sobre las causas que propiciaron en Alemania el cambio a un régimen totalitario y sobre los nefastos efectos inmediatos. La acción gira en torno a un caso real de espionaje cuyo sensacionalista desenlace ocupó la prensa internacional durante algunas semanas. El texto, que al cabo de tres cuartos de siglo resulta turbador por su carácter premonitorio, documenta de primera mano los entresijos de unos hechos tan sólo someramente conocidos. De paso, Maslow ofrece una semblanza política y cultural de Berlín entre 1928 y 1933 así como de las andanzas de un variopinto grupo de alemanes en el exilio parisino, episodio en el que haremos especial hincapié, a la vez que explicaremos los vericuetos del manuscrito.
\end{abstract}

Palabras clave: literatura testimonial, nazismo, espionaje, memoria histórica, exilio alemán.

Live memory: The general's daughter, an unpublished novel by Arkadij Maslow

\begin{abstract}
Arkadij Maslow (1891-1941), a communist politician during the Weimar Republic and since 1933 in Paris exile, finished in 1935 an eye-witness novel about Hitler's surge to power, the underlying causes for the switch in Germany to a totalitarian regime and its immediate evil effects. The plot focuses on a real case of espionage and its sensationalist outcome which kept the international press busy for several weeks. The text is a first-hand document whose premonitory nature, 75 years later, is still astonishing in its freshness and immediacy. Apart from a close account of these occurrences which were known mainly by hearsay, Maslow offers a political and cultural view of pre-war Berlin from 1928-1933, and afterwards, of the vicissitudes which German exiles underwent in Paris, an episode we shall dwell on especially.
\end{abstract}

Key words: literary testimony, Nazism, espionage, historical memory, German exile. 
El presente artículo es resultado de una investigación llevada a cabo para una edición histórico-filológica de la primera y única novela de Arkadij Maslow, inédita hasta la fecha. Más que emprender una crítica literaria propiamente dicha, mi introducción y anotaciones pretenden abarcar diversos aspectos del momento histórico en el que se desarrolla la novela de Maslow ${ }^{1}$.

La literatura testimonial suscita, de algunos años a esta parte, un creciente interés también en España. Enfrentarse con el propio pasado es un ejercicio que deben abordar, tarde o temprano, las conciencias traumatizadas o las meramente sensibles a tales temas. Por mucho que a veces se quiera negar la existencia o vigencia de este pasado, de nada sirve echar mano del argumento de que hay que mirar al futuro y que no se deben reabrir viejas heridas. El pasado indigesto es como una chinita en el zapato: no te permite andar hasta que no te la sacas de dentro. Con nuestros países pasa lo mismo. Si no se aceptan ni se asimilan los hechos del pasado con todos sus claroscuros, tienden a regresar y manifestarse de forma cada vez más virulenta. Los pueblos deben poder enfrentarse con su propio pasado, por embrollado, vergonzoso o chocante que éste pueda resultar. Al igual que no sería moralmente defendible dejar en herencia a nuestros hijos y nietos un medio ambiente contaminado ni una naturaleza saqueada, tampoco sería honroso legarles una historia falseada u oculta de su país, es decir, un pasado que ha quedado inoculado de un maligno virus latente ${ }^{2}$. A pesar de los múltiples y graves problemas del presente y del futuro de los pueblos (que todos los tienen), éstos nunca deben obviar los hechos irresueltos, no del todo digeridos, de su pasado.

En Alemania se emprendió el camino de la catarsis o del examen de lo que se ha dado en llamar conciencia colectiva ya en los años sesenta, con los procesos de Auschwitz y el televisado juicio a Adolf Eichmann. Esa confrontación con el propio pasado culpable, su debate en el seno de la familia y su revaloración oficial ha sido un ejercicio doloroso, pero imprescindible. Sólo con esos deberes hechos -con el pasado deglutido, por indigesto que fuera- se ha podido regresar con un grado de credibilidad al concierto de las naciones y a un estatus de socio internacional de pleno derecho en el terreno político, cultural y económico. Ha habido un reconocimiento, desde las instituciones del Estado, de lo que significó el Holocausto y de cuál debe ser la manera de presentar esos hechos históricos al mundo y a las futuras generaciones de alemanes, un reconocimiento sin trabas ni medias tintas. Para poder configurar un panorama con visos a una máxima exactitud, en cuanto a los datos y los móviles que generaron esos hechos, se ha contado con todo tipo de documentos oficiales y extraoficiales.

\footnotetext{
1 Una versión reducida de este artículo se presentó como comunicación el 25 de mayo de 2010 en el Congreso Internacional "Espacios y Escrituras del Exilio", celebrado en la Universidad Complutense de Madrid. Entretanto, el estudio crítico preliminar y la edición filológica de la novela han sido aceptados para su publicación, en la primavera de 2011, en la be.bra-Verlag de Berlín.

${ }^{2}$ La cita de Marcelino Menéndez Pelayo "Pueblo que no sabe su historia es pueblo condenado a irrevocable muerte. Puede producir brillantes individualidades aisladas, rasgos de pasión de ingenio y hasta de género, y serán como relámpagos que acrecentará más y más la lobreguez de la noche" (Historia de los heterodoxos españoles, 1880), fue reinterpretada por George Santayana al decir "Those who cannot remember the past are condemned to repeat it" (The Life of Reason, 1905). La misma o parecida frase se ha visto convenientemente manipulada y trastocada, a diestra y a siniestra, hasta convertirla en "un pueblo que olvida su historia está condenado a revivirla". Así y todo, no deja de ser muy cierta.
} 
Partiremos del supuesto de que la literatura es siempre un documento extraoficial. Para ser más exactos, la literatura que da cuenta de ese proceso dialogante con la propia historia es de tipo variado. Va de lo autobiográfico, en forma de diario privado o de crónica generacional, a los testimonios de implicados y afectados, pasando por la acusación directa hacia la generación de verdugos por parte de las víctimas así como de los hijos de verdugos y víctimas ${ }^{3}$. Contamos también con una literatura del exilio alemán que en más de una ocasión narra, desde el lugar de acogida, directa e indirectamente, las peripecias personales o compartidas ${ }^{4}$. En general, se intenta encontrar una respuesta a la pregunta de cómo fue posible el cataclismo, quiénes lo fomentaron y por qué no se pudo evitar. El marasmo en que Alemania se hundió, durante doce largos años, arrastró no sólo a sus vecinos inmediatos sino al mundo entero. Sobre todo después de la caída del muro y del desmembramiento del bloque comunista, se empezó a ver con nuevos ojos -más imparciales, más limpios de prejuicios y también implacables- cuáles habían sido las causas, cuáles son hoy los datos comprobables, los hechos públicamente reconocibles, que hicieron que Alemania desembocara en esa especie de agujero negro abierto en la historia de la humanidad.

La novela de Arkadij Maslow que aquí nos ocupa ha sido un hallazgo por varios motivos: hasta ahora era prácticamente desconocida la faceta literaria de Maslow, quien tenía cierto renombre como político de la izquierda en la República de Weimar, pero no como novelista ${ }^{5}$. Cuando tuve noticia de que este texto se hallaba inédito en una de las bibliotecas de manuscritos raros de la Universidad de Harvard, decidí recuperarlo sin saber de antemano cuál era su argumento ni cuáles habían sido las tesis que defendía el autor ni el enfoque histórico que en él pretendía transmitir. Descubrí su alcance mientras fui mecanografiando los 554 folios del original que, en papel cebolla, se encuentra en muy mal estado, lleno de rasgaduras y tachaduras, por lo que no se permite fotocopiarlo.

\footnotetext{
3 Algunos de los ejemplos más destacados de esta literatura en Alemania y Austria son los títulos siguientes, accesibles también en traducción española: Anónima, Un mujer en Berlín, Madrid: Anagrama, 2005; Hans Beimler, En el campo de asesinos de Dachau. Cuatro semanas en poder de los bandidos pardos, Barcelona: Europa-América, 1937; Primo Levi, Si esto es un hombre, Barcelona: El Aleph, 1999; Jean Améry, Mas allá de la culpa y de la expiación, Valencia: Pre-Textos, 2001; Victor Klemperer, Diarios 19331945, Madrid: Galaxia Gutenberg, 2003; Jorge Semprún, La escritura o la vida, Barcelona: Tusquets, 1996; Elie Wiesel, Trilogía de la noche, Barcelona: El Aleph, 2007; El diario de Ana Frank, México: Bernera Editores, 2007; Jan Erik Vold (ed.), El Diario de Ruth Maier, Madrid: Debate, 2010; Hélène Berr, Diario, Madrid: Anagrama, 2010; Harald Weinrich, Leteo: arte y crítica del olvido, Madrid: Siruela, 1999; la película documental de Malte Ludin, 2 oder 3 Dinge, die ich von ihm weiâ [2 o 3 cosas que sé de él], Berlinale 2005.

4 André Simone (ed.), El libro negro del terror nazi en Europa, México: El Libro Libre, 1943; Renata von Hanffstengel / Cecilia Tercero, México, el exilio bien temperado, Puebla: UNAM / Instituto de Investigaciones Interculturales Germano-Mexicanas / Instituto Goethe, 1995; Ana Pérez (ed.), El exilio alemán (1933-1945). Textos literarios y políticos, Madrid: Librería Marcial Pons, 2008.

5 Maslow escribió una biografía novelada de Stalin y un esbozo para un novela sobre la Revolución Francesa, según se desprende de los papeles inéditos de su legado, depositado por Ruth Fischer en la biblioteca Houghton de la Universidad de Harvard. En la revista de Praga Neue Deutsche Blätter publicó Maslow en 1933 una columna, así como en el núm. XXX (1937) de Neue Weltbühne de París. También escribió diversas columnas en las revistas del exilio alemán Pariser Tageblatt (con el seudónimo Malam) y editó, a partir de enero de 1939, los dos únicos números de Cahiers d'Europe, cf. Maas (1981), Peterson (1987) y Charle (2004).
} 
Maslow, cuyo nombre verdadero era Isaac Chemerinski, nació en Jelisavetgrado, hoy Kirovogrado (Ucrania), en 1891 y llegó a Berlín, con su madre y su hermana, alrededor de 1900, que es cuando aprendió alemán, en adelante su lengua de trabajo. Cursó bachillerato y estudios de piano en Berlín y Leipzig para posteriormente matricularse, en la Universidad de Berlín, en Matemáticas y Física y asistir, entre otros, a cursos de Albert Einstein y Max Planck. En 1916 se unió a la Liga Espartaquista, una unión de marxistas revolucionarios. Tras el asesinato de Rosa Luxemburg y Karl Liebknecht, en enero de 1919, se fue radicalizando políticamente. A ello contribuyó su contacto con Ruth Fischer ${ }^{6}$, una conocida activista comunista de aquel entonces, que hizo que adoptara el seudónimo de Arkadij Maslow como nom-deguerre $^{7}$. Allá donde ella era la voz audible, él era el intelecto organizador. Ambos mantuvieron posturas revolucionarias de una izquierda cada vez más discrepante del discurso oficial que se dictaba desde Moscú, lo que en 1924 les valió la expulsión del KPD (Partido Comunista Alemán), sin que por ello se acercaran jamás a la socialdemocracia. Más cercanos a las doctrinas de Lenin, siguieron trabajando en células de Berlín y entraron en contacto con Trotsky, pero tampoco llegaron a suscribir la línea de éste. Realmente fueron unos "renegados en contra de su voluntad", como reza la colección de correspondencias y ensayos de ambos (Lübbe 1990).

La primera y única novela de Maslow, que arranca en los últimos años de la República de Weimar, gira en torno a unos acontecimientos que se produjeron dos años después de la marcha de la pareja al exilio. Pero el autor explica cómo pudieron gestarse y porqué tuvieron ese desenlace, relatándolos con una veracidad realmente asombrosa en cuanto a personajes reales e inventados. Los incidentes históricamente documentados y las figuras que en ellos intervinieron pasan por el filtro de una óptica fuertemente satírica, en la mejor herencia heineana, lo cual es todo un acierto, ya que le permite a Maslow hacer una denuncia que, a pesar de su proximidad a los hechos, con el paso del tiempo ha resultado ser certera y clarividente en su valoración.

Cuando Maslow y Fischer escaparon de Berlín, en marzo de 1933, se dirigieron en moto a Praga para viajar posteriormente a París. Allí trabajaron en la prensa del exilio, uniéndose en una supuesta causa común a los grupos de antifascistas recién salidos de la Alemania hitleriana. Pero eran, a la vez, fervientes disidentes de los secuaces más cerriles de Stalin, y esa incondicionalidad suya les valió el título de

${ }^{6}$ Ruth Fischer nació en Leipzig, el 8 de diciembre de 1895, como Elfriede Eisler. Su padre fue el profesor vienés Rudolf Eisler, su madre Ida Maria se llamaba Fischer de soltera. Su hermano Gerhart ocuparía más tarde un destacado puesto del Komintern y a partir de 1949 dirigió la Oficina de Información de la RDA. El otro hermano, Johannes, fue un compositor renombrado (cfr. Betz 1982).

7 Ruth Fischer cuenta de la manera siguiente cómo se generó este seudónimo: "Tras el asesinato de Karl Liebknecht y Rosa Luxemburg, el 15 de enero de 1919, la Liga Espartaquista tuvo que pasar a la clandestinidad. A todos los miembros del partido se les pidió que adoptaran un seudónimo. Maslow llegó a esa reunión con el bocadillo bajo el brazo, una botella de cerveza y un trozo de mantequilla. Al ser preguntado qué nombre deseaba adoptar dentro del partido contestó que Butejlkin -hombre-botella- o Maslow -hombremantequilla-. Los camaradas se decidieron por "Maslow" porque era más fácil de pronunciar para las lenguas alemanas" (apud Lübbe 1991: 541). La traducción es mía.

8 El fenómeno de las "conversiones" o transfuguismos políticos es estudiado por Betz (1982), Crossman (1949) y Deutscher (1969). 
rara avis en el seno de los antifascistas ${ }^{9}$. Maslow, que había escapado con su familia de los pogromos y de la persecución por parte de los cosacos, estaba al tanto de las purgas llevadas a cabo en la URSS y de las matanzas de civiles por hambrunas, entre 1929 y 1934, en su Ucrania natal, un verdadero genocidio cuya realidad, tildada de propaganda anticomunista, se ha querido negar durante décadas. Ahora bien, la causa común que debía unir a todos los intelectuales alemanes exiliados en París era luchar con la pluma por un pronto derrocamiento del fascismo en Alemania.

La hija del general pretende, ante todo, desenmascarar la fantochada de un bigotudo megalómano que amenazaba con arrollar a Europa entera. La verdad en directo, narrada por un testigo de primera mano, rezuma por todas partes en esta novela y convence por sí sola, por su inmediatez y frescura. Y la denuncia contundente de las perversidades históricas la consigue Maslow a través de la parodia, la sátira y la caricatura $^{10}$. Lo que narra se basa en la propia observación y en información obtenida de testigos directos y a través de medios clandestinos. El manuscrito lleva una serie de tachaduras que resulta difícil determinar si son del propio autor o de su concienzuda lectora Ruth Fischer ${ }^{11}$. Según se desprende de la correspondencia de ambos, Bertolt Brecht leyó la novela en 1941 y le pareció buena. Maslow la mandó a una editorial inglesa, pero no estaba dispuesto a realizar los cambios que le exigían, y la novela se quedó sin publicar. Cuando Maslow y Ruth Fischer tuvieron que huir de París ante la llegada de las tropas nazis, en junio de 1940, una copia cayó en manos de la Gestapo, pero Gerhart Friedländer, el hijo de un temprano matrimonio de Ruth Fischer, conservaba otra copia, que es presumiblemente la que actualmente se halla depositada en Harvard. La huida de Maslow y Fischer, con documentos falsos y bajo diversos nombres, les llevó por Marsella y Portbou, a través de la España franquista, a Lisboa donde se quedaron atrapados a la espera de obtener un visado para Estados Unidos ${ }^{12}$. Ruth Fischer lo consiguió en febrero de 1941 y decidió

9 Todavía no se había producido el pacto entre Hitler y Stalin, aunque ya estaban llegando las primeras noticias de las purgas y procesos sensacionalistas contra reconocidos líderes comunistas. Ruth Fischer publicaría posteriormente Stalin and German Communism. A Study in the Origins of a State Party, Cambridge: Harvard University Press, 1948, y Die Umformung der Sowjetgesellschaft: Chronik der Reformen 19531958, Düsseldorf: Diederich, 1958.

${ }^{10}$ La parodia que hace Maslow de un discurso de Alfred Rosenberg (1893-1946), ideólogo del racismo nazi, no tiene pérdida en cuanto a lo absurdo y nebuloso de tal pensamiento y los más que obvios móviles psicológicos subyacentes a tan colosal estupidez que iban tener tan trágicas consecuencias.

11 El cotejo grafológico de la letra con la que aparece en una contraportada manuscrita en 1944, tres años después de la muerte de Maslow, nos hace suponer que las tachaduras y enmiendas son de su lectora y correctora Ruth Fischer.

${ }^{12}$ Lo precario de una huida así queda reflejado en el siguiente testimonio de Karl Retzlaw (1971: 382 383), quien pocas semanas más tarde recorrería el mismo camino de Maslow y Fischer: "Cuando [en Banyuls] me devolvieron mi pasaporte sin el permiso de salida, subí un mediodía, bajo un sol abrasador, el empinado camino hasta el puesto fronterizo español. Sellaron mi pasaporte y me ordenaron reportar a la policía de Port Bou. En la comisaría de allí, al lado del oficial español, estaba sentado un alemán de la Gestapo que hojeaba un libro de personas en busca y captura. Comparó mi nombre con los de su libro. Hacia mediodía del día siguiente me encontré en Barcelona. Visité la ciudad y seguí camino de Madrid en el tren nocturno. Hubo varios controles de la brigada criminal. En la estación de Madrid vi en los andenes soldados marroquíes armados hasta los dientes, con sus ropajes de color y sus uniformes. El tren para Lisboa no salía hasta la noche. Durante el día recorrí Madrid y llegué a una gran cárcel, en medio de la ciudad. Detrás de cada reja de las ventanas sin cristales se asomaban varios presos republicanos, de los cuales la mayoría nunca recuperaría la libertad. [...] En la estación de Lisboa había un centenar de refugiados esperando a sus familiares o conocidos y que preguntaban a los que llegábamos si habíamos conocido o visto a ese o aquel. Me contaron 
embarcarse dos meses más tarde, dejando atrás, muy a su pesar, a su compañero que finalmente, en mayo de 1941, obtuvo permiso de zarpar para Cuba. Medio año después, Fischer le anunciaba desde Nueva York que había conseguido el visado para él, pero a Maslow ya de nada le sirvió, pues el 21 de noviembre del mismo año le encontraron desmayado en un callejón de La Habana después de haber cenado en perfecto estado de salud en un restaurante chino. No volvió a recuperar el conocimiento y murió al día siguiente. Nunca se supo a ciencia cierta la causa de su fallecimiento $^{13}$. Medio año antes, el propio Maslow había presagiado que

las personas amenazadas por Stalin [...] tienen mucho que temer. El que yo pertenezco a esa categoría de personas es un hecho conocido y por así decirlo, jurídicamente notorio. Fui condenado indirectamente a muerte en agosto de 1936 durante el proceso Sinoviev-Kamenev, cuando un hombre sobornado (y luego ajusticiado) manifestó que yo le había enviado a Moscú para asesinar a Stalin. Seguro que yo no hubiera lamentado que a Stalin le ocurriese lo que declaró ese hombre, pero no se hizo esa declaración porque estuviese en peligro sino para poder mandarme al otro barrio a la mínima de cambio. (Lübbe 1990: xv)

Ruth Fischer, que murió en 1961 en París, dedicó el resto de su vida a demostrar que fueron los esbirros del dictador soviético quienes habían liquidado a Maslow como elemento demasiado incómodo ${ }^{14}$. Esas circunstancias hacen del presente manuscrito inédito un documento de la barbarie totalitaria y un objeto de especulaciones diversas sobre la suerte de su autor. De hecho, faltan seis páginas del original cuyo contenido se desconoce, pero es muy probable que Fischer o el propio Maslow, al retirarlas, quisieran suavizar la diatriba contra los espías y delatores estalinistas para dar una apariencia de mayor concordia en el frente popular que se pretendía formar contra el fascismo. De modo que, salvo escasas pinceladas que versan sobre las tensiones entre los emigrantes, se trata de un alegato muy eficaz contra el nazismo. Es una memoria en diferido, pero a una distancia tan corta que casi convierte la novela en protocolo de unos hechos delictivos.

Cuando en enero de 1933 el gobierno de Alemania fue a parar a manos de los nacionalsocialistas, éstos comenzaron una verdadera caza de brujas de todos los

\footnotetext{
que actualmente vivían unos 4000 refugiados en Lisboa que todos esperaban un visado, un barco o un avión que debía llevarlos a ultramar. [...] Supe que el punto de encuentro de los refugiados era la Avenida da Liberdade. Cuando llegué allí, vi a un millar de refugiados, sentados en los bancos o paseándose. Encontré a Babette Gross, que me preguntó por Willi Münzenberg. También Maslow, Ruth Fischer, Arthur Koestler, el médico berlinés Benno Lewi que me había tratado en París, Walter Mehring y otros conocidos". La traducción es mía.

13 Esta misteriosa muerte recuerda a otros casos de nuestra época actual, como el intento de asesinar a Víctor Yushchenko o el asesinato consumado de Alexander Litvinenko.

14 Recordemos que idéntica suerte corrieron León Trotsky, Andreu Nin y -existen sospechas en este sentido- también Buenaventura Durruti. El espía soviético Alexander Orlov fue responsable directo de los asesinatos, en 1937, de Kurt Landau, Mark Rein, Camilo Bernieri y José Robles Pazos. De entre los antiguos compañeros de viaje de Maslow y Fischer, cayeron víctimas de las purgas estalianianas Artur Golke, Leo Flieg, Hugo Eberlein, Fritz Schimanski y Max Hölz. Por otra parte, la enardecida campaña antistaliniana de Ruth Fischer la llevaría, a finales de los años 40 y principios de los 50, a aproximarse a la CIA y al mccarthysmo. Como "Alice Miller" parece ser que llevó a cabo labores de espionaje, durante ocho años, en algún momento entre 1942 y 1955, para la CIA en el grupo clandestino "The Pond".
} 
adversarios políticos. Tras el incendio del Reichstag, el clamor popular provocado por este hecho, manipulado por la propaganda de Goebbels, propició un cambio inmediato del sistema legal -la perversión completa de la Justicia- que a partir de entonces autorizaba cualquier acción policíaca represiva. Fue creada la Gestapo y su red de espías; se establecieron los primeros campos de trabajo, a los que en esa fase inicial fueron a parar sobre todo los sospechosos de izquierdismo. Hitler revocó inmediatamente las reparaciones y las restricciones para la industria armamentística impuestas a Alemania en el Tratado de Versalles. Así que la mayoría de las grandes empresas colaboraron, o se vieron forzadas a ello para sobrevivir, en la producción de material bélico de todo tipo ${ }^{15}$. El que se empezaran a hacer preparativos para una nueva guerra lo percibió nuestro autor con total claridad cuando la admiración internacional por el relanzamiento de la economía alemana era aún la tónica general.

La hija del general narra, pues, bajo nombres inventados ${ }^{16}$, el caso verdadero de la nuera de un conocido general de la Primera Guerra Mundial ${ }^{17}$, la cual terminó ejecutada por alta traición. El caso de Benita von Falkenhayn y Renate von Natzmer, dos miembros de la aristocracia berlinesa acusadas de espionaje para el Partido Comunista, agitó a la prensa internacional durante algunas semanas. Fueron acusadas de haber cometido alta traición y condenadas por el recién fundado Tribunal Popular en un juicio sumarísimo. Murieron el 16 de febrero de 1935, decapitadas con un hacha de mano, en la prisión berlinesa de Plötzensee. Aunque tal argumento novelístico pueda parecer sensacionalista, Maslow lo sustenta con toda suerte de referencias al clima mental de la época, describiendo minuciosamente el ambiente político y social que propició la llegada del nazismo y la perversión de la justicia. Los entresijos de este nuevo sistema "normalizado" los pudieron entrever el autor y sus allegados. El relato de las aberrantes estructuras legales instauradas por el Tercer Reich ha quedado de sobra corroborado (Koch 1989; Müller 1991; Evans 1996).

Lo que no pudo prever Maslow en su novela era que ese camino estaba abocado a una nueva guerra mundial. Como otros muchos exiliados, pensó que su condición sería temporal y que de alguna forma se restablecería a corto plazo un régimen democrático en Alemania. Bajo tal prisma histórico, el texto de 1935 cobra un ominoso carácter premonitorio. Pero tampoco pudo imaginarse su autor el Holocausto - tal monstruosidad no cabía en la imaginación siquiera de los más críticos con el régimen nazi-. En su novela, Maslow hace la siguiente reflexión sobre la persecución de los judíos en Alemania:

${ }^{15}$ Existen hoy estudios detallados sobre la involucración en el rearme nazi de, entre otras muchas empresas, Siemens, AEG, Degussa, Krupp y Thyssen, así como del Dresdner y del Deutsche Bank (cfr. Beyerchen 1977; Cornwall 2003; Hayes 2004; Feldenkirchen 1995; Feldman 2002; Simpson 2002; Wiesen 2001). También se ha intentado explicar por qué la ciencia se puso al servicio del nuevo régimen sin mayores problemas de conciencia (cfr. Herf 1984; Guérout 1992; Neufeld 2002).

${ }_{16}$ Las figuras de Marieluise y Marianne von Bimmelburg se inspiran en las verdaderas hijas del general de la Reichswehr Barón von Hammerstein-Equord, figura que ha sido recientemente recordada por Hans Magnus Enzensberger en Hammerstein oder der Eigensinn, Frankfurt / Main: Suhrkamp, 2008.

${ }^{17}$ Hindenburg, Falkenhayn y Ludendorff fueron los tres generales más destacados en las filas alemanas durante la Gran Guerra (cfr. Conard 1923). 
[E]l verdadero grueso de la emigración alemana lo constituyen los judíos. El antisemitismo zoológico de Alemania, atizado ideológicamente -si es que tal estafa intencionada puede llamarse ideología- por unos tenaces envenenadores de la ralea de Rosenberg, el aventurero báltico, o del sádico pornógrafo [Goering?], y ejecutado con alemana sistematicidad y meticulosidad, ahuyentó desde el principio a muchos judíos del Reich. Todos se llamaban emigrantes y se siguen llamando así; el presente desarrollo de los hechos hará que en el futuro no se le podrá negar ese título a ningún judío alemán: los nazis quieren hacerles la vida imposible a los judíos en Alemania ${ }^{18}$.

La novela tiene siete partes y está dividida en veintiún capítulos. La primera parte, "El proyecto", alude a las maniobras de los allegados de Hindenburg, el viejo Presidente de la República, para mantenerse en el poder. También presenta la situación familiar del general von Bimmelburg, trasunto de Hammerstein-Equord, una de cuyas hijas, la modosa e impresionable Marieluise ${ }^{19}$, se convierte en amante de Gerhard Alkan, abogado comunista, probable alter ego a su vez del conocido político Walter Scholem ${ }^{20}$. La otra hija es presentada como más moderna y pragmática, muy de los locos años veinte; tiene relaciones cambiantes y una actitud de muchacha liberada algo cínica. Marieluise roba unos documentos de escasa importancia de la caja fuerte de su padre para hacerlos llegar a su amante comunista. Su primo Lippentroff (von Ribbentrop) ${ }^{21}$, que abusó de ella cuando niña, está al tanto e intenta comprometer a la hija y al padre, denunciándolos a la Gestapo. De hecho, se les tiende pérfidamente una trampa en la que acaban cayendo. Ahora sabemos que todo el país cayó con ellos en esa trampa.

En la segunda parte de la novela que lleva el epígrafe "Hay que aullar con los lobos", lo que en alemán quiere decir algo así como "seguirle la corriente al que es

18 Traduzco libremente estos y los siguientes pasajes del manuscrito inédito de Maslow, por lo que no puedo citar aún ni la edición ni el número de página.

19 Kurt von Hammerstein-Equord estaba casado, desde 1907, con Maria, hija del Barón Walther von Lüttwitz (1859-1942) que después de 1918 fue General del Reichswehr en Berlín y corresponsable, en 1920, de un sonado intento de golpe de Estado (Kapp-Putsch). Los Hammerstein-Equord tenían, a diferencia de los Bimmelburg, cuatro hijas (Marie Luise, Maria Therese, Hildur y Helga) y tres hijos (Kunrat, Ludwig y Franz). Dos de los hijos varones, Ludwig und Kunrat (1918-2007), pertenecieron al círculo de los que planearon el atentado del 20 de julio de 1944 contra Hitler. Dos de las hijas, Marie Luise (1908-1999) y Helga (1913-2001) ingresaron en el Partido Comunista en 1929 y 1930 y pasaron a Moscú unos documentos de la caja fuerte de su padre. Marie Luise estuvo sentimentalmente ligada al diputado comunista Werner Scholem, y su hermana Helga con Leo Roth, fusilado durante los Procesos de Moscú. La tercera hija, Maria Therese (1910-2000), huyó en 1934 con su marido judío a Palestina.

20 Werner Scholem (1895-1940), hijo del propietario de una imprenta, fue periodista y diputado comunista en el Parlamento alemán. En agosto de 1926 fue expulsado del partido, junto a Arkadij Maslow, Ruth Fischer y Hugo Urbahns; en 1927 fueron expulsados asimismo Paul Schlecht y Guido Heym. Nada más llegar Hitler al poder, Scholem fue deportado, por ser judío, al campo de concentración de Dachau y posteriormente asesinado en Buchenwald. Urbahns (1890-1946) pudo huir por Checoslovaquia a Suecia; Schlecht (1882-1947) posteriormente regentó una taberna en Berlín, punto de encuentro de grupos clandestinos de izquierdas, y Heym (1882-1945) fue fusilado por las SS.

21 El posterior Ministro de Asuntos Exteriores de Hitler Joachim von Ribbentrop estaba casado desde 1921 con una heredera de la fábrica de vinos espumosos Henkell. En mayo de 1925 fue adoptado por su tía lejana Gertrud von Ribbentrop (1863-1943), cuyo padre Karl Ribbentrop había obtenido el título nobiliario en 1884. Desde entonces, el vanidoso y ambicioso Ribbentrop pudo llevar el "von" en su nombre. Maria Baronesa von Lüttwitz, el modelo real para Adelheid von Bimmelburg, no tenía, sin embargo, ningún tipo de parentesco con Ribbentrop. 
más fuerte que tú", vemos que Marianne se alía con un tal Mészaros - este nombre en húngaro significa carnicero-, ahora jefe de la Gestapo y antiguo capitán de caballería del Imperio Austrohúngaro ${ }^{22}$. El asunto del robo de documentos, que podría comprometer al personaje público que sigue siendo el general von Bimmelburg, es encubierto por la justicia, profundamente corrompida, mediante un trato, con el cual posteriormente puede chantajear a las hijas. Maslow describe los métodos de interrogación seguidos por Paul Vogt, el instructor real del caso de Van der Lubbe, el holandés acusado de incendiar el Reichstag. También se hace un estudio de las intrigas y cambalaches de los personajes históricos Schleicher ${ }^{23}$, von Papen $^{24}$ y Gregor Strasser $^{25}$ en sus negociaciones con el viejo Presidente de la República, que finalmente aúpan a Hitler como mal menor.

La tercera parte, "Los tiempos están desquiciados", narra la desorientación de ambas hermanas que se prestan a espiar a diestro y siniestro para salvar el buen nombre de su padre ${ }^{26}$. Éste, mientras tanto, toma parte en una conspiración para prevenir el ascenso de Hitler. Se reúne en un lugar secreto con Schleicher y Strasser, aunque de tal encuentro secreto nada haya trascendido nunca. A través de la psicología de los conspiradores se explica el titubeo, la venganza personal, la envidia y la falta de visión política que hacen que todas las iniciativas por parar la ascensión de los nazis queden en agua de borrajas:

Magníficos eran todos los planes que ese año se tramaron en todas partes. Planes políticos, planes personales, planes de partido. Los generales planeaban desfilar, los nazis desfilaron. Los comunistas se manifestaron como nunca lo habían hecho; bajo un frío glacial, millares de obreros decididos se sumaron a la marcha por delante la casa de Karl-Liebknecht en Berlín con el puño levantado, Thälmannn por delante de ellos con el puño levantado, y todos estaban determinados a no permitir jamás, jamás que vencieran los fascistas. Unos días después, la casa KarlLiebknecht se halló ocupada por la policía del presidente nazi. Hindenburg había jurado que mientras ÉL viviera, el "suboficial bohemio" nunca, nunca llegaría a ser canciller del Reich. No tardó mucho en convocar él mismo al "Señor Hitler", y Papen, quien había vociferado en contra de la "arrogante reclamación de un solo partido" y que no toleraría jamás, jamás la autocracia de un único partido, había

\footnotetext{
22 Aunque nuestro autor no los nombre explícitamente, este personaje parece tipificar unos tempranos Reinhard Heydrich, el "carnicero" de Bohemia y Moravia, o Heinrich Himmler, sucesor de Rudolf Diels como jefe de la Gestapo.

${ }_{23}$ Kurt von Schleicher (1883-1934), general del Reichswehr y último canciller de la República de Weimar, persuadió a Hindenburg para que el 1 de junio de 1932 nombrara a Franz von Papen sucesor de Brüning, sólo para tramar su cese poco después. El 2 de diciembre, Schleicher se convirtió él mismo en canciller, pero sólo se mantuvo 57 días en el puesto, gobernando, al igual que sus predecesores inmediatos, mediante decretos-ley.

${ }^{24}$ Franz von Papen (1879-1969), miembro del partido católico centrista durante la República de Weimar y brevemente canciller, contrincante de Schleicher, felicitó a Hitler por el asesinato de éste durante la acción de "limpieza" conocida como la "Noche de los Cuchillos Largos". Entre 1934-1939 fue embajador de Hitler en Austria y ficha clave para su anexión (cfr. Rolfs 1969, y Madariaga 1974).

${ }_{25}$ Gregor Strasser (1892-1934) reorganizó decisivamente el partido nacionalsocialista, pero chocó por su postura anticapitalista con las ambiciones de Hitler quien mandó asesinarle con la excusa de una supuesta conspiración.

26 El tema del espionaje en todos los frentes es estudiado por Gelibter y Melé (1971) y Koch (1994).
} 
llevado a Hitler ante Hindenburg. Schleicher, el "general social", había sido derrocado y los sindicatos, contra los que nadie en Alemania "puede gobernar ni veinticuatro horas", habían resultado ser unas asociaciones sin resistencia ni voluntad, mortificando todo espíritu de lucha. [...] La componenda de la triste república alemana que nunca había creído en sí misma se había derrumbado como un edificio chapucero carente de cimientos, de muros sólidos o tan siquiera de una bonita fachada. Esa república murió de muerte propia.

La parte siguiente de la novela, "Liaisons dangereuses", describe el clima reinante entre los emigrantes alemanes en París. Allí pululan elementos de toda laya, algunos también desorientados, acomodaticios y frívolos, otros perseguidos o espiados, muchos instigadores o sufridores de intrigas internas. Las "amistades peligrosas" se refieren a los vínculos que algunos exiliados mantienen con embajadores y subalternos de ambos totalitarismos. Todo el mundo conspira, denuncia, delata y espía $^{27}$. En definitiva, Maslow pinta aquí un fresco muy poco alentador de aquel maremagno de desterrados que, como integrante y sufridor, conocía muy bien. El hecho de que se pusiera mayor acento en la variedad entre los emigrantes que en una procedencia y causa comunes y que la lucha por imponer la propia postura se antepusiera a la voluntad y la capacidad de solidarizarse, fue el rasgo más negativo del grupo de emigrantes alemanes en París. Así que Maslow no describe como solidario con alguien o con una causa a ninguno de sus personajes lo. En el capítulo doce “¡A París! ¡A Paris!” leemos:

Pronto cesó la solidaridad mutua entre los partidos perseguidos, y cuanto más hablasen y escribiesen sus cabecillas emigradas más tarde sobre la "unidad" y los "frentes", tanto más pertinaz era su deseo de hacerle al compañero y a los "amigos”, según rezaría pronto ese dulzón término, la zancadilla política.

El compromiso político tan urgente, la unión solidaria de todos los partidos y facciones en el exilio, la lucha por restablecer la democracia en Alemania, se representa como algo cada vez más absurdo, debido a la falta de orientación e imaginación y la irresistible atracción del ocio, la francachela y el placer de vagar por la ciudad:

En París no existía ninguna ocupación razonable para los emigrantes alemanes; de hecho, muchas veces no había ninguna ocupación en absoluto para esa gente arrojada de su patria, y lo que tenían por "ocupación" -acaso no se habían camuflado como pudieron con una profesión provisional en unas condiciones infinitamente difíciles-, los precipitados aspavientos sin rumbo que llamaban "política" de la emigración, pues, los ejercían, a decir verdad, sólo los cabecillas, en parte sólo consistía en un constante vaivén entre una docena de conocidos cafés en unos barrios conocidos adonde uno se desplazaba para "encontrarse" con otros como por casualidad. Esta categoría de emigrantes se movía siempre en el mismo cír-

27 En París se hallaban a la sazón los siguientes personajes, hoy reconocidos como espías: Georges Pâques; Alexander Mijailowitch Orlow alias Leiba Felbing; Josef Romualdovitch Grigulevitch; Mark Zborowski; Theodor Maly alias Paul Hardt; el "mensajero" Arnold Finkelberg; Leopold Trepper alias Otto, Adam Mickler o Jean Gilbert; Walter Krivitzki y Rudolf Abel. 
culo, geográfica e ideológicamente hablando, por lo que incluso el encuentro más casual y sorprendente en el fondo no podía serlo.

Aunque el panorama de estancamiento que Maslow pinta aquí parezca desalentador, lo cierto es que se correspondía con la realidad de la época. Al reproducir sin adornos esos hechos, el autor quiso ser algo más que un mero aguafiestas. Su descarnada denuncia queda apoyada por una serie de documentos hoy disponibles. Liselotte Maas así lo corrobora:

En las salas de espera Praga y París, los emigrantes alemanes esperaban un pronto final de lo incomprensible que tenía lugar en casa, y entretanto intentaban -no en último lugar, mediante los periódicos- conservar lo que habían perdido. Pero su concepción del régimen de Hitler como un interregno terrible, pero breve se reveló cada vez más como una ilusión. (Maas 1981:17)

También es cierto que la batalla con la pluma, tras haber conseguido Willi Münzenberg ${ }^{28}$ un revuelo internacional por el affaire del incendio del Reichstag, había ido degenerado hasta fijarse únicamente en aspectos de colorido local. La prensa alemana en el exilio tendía a proporcionar orientación y mediación práctica a los recién llegados a París, por lo que había dejado de ser un arma eficaz para la lucha contra el régimen de Hitler ${ }^{29}$.

En la parte quinta de la novela, titulada "La metralleta perfecta", se describen con todo detalle los secretos planes de rearme llevados a cabo por el ministerio de Göring con la connivencia de la gran industria ${ }^{30}$. A la vez, la acción regresa a la trama de las hermanas Bimmelburg y de sus andanzas entre lobos. Marieluise se ha vuelto sexualmente dependiente de un apuesto diplomático polaco, por el que comete actos de espionaje en el Ministerio de Defensa en donde ella ha encontrado un empleo gracias a su apellido. Su hermana Marianne sigue moviéndose en los círculos de la alta burguesía berlinesa y espiando para la Gestapo, pero alimenta a la vez simpatías por la lucha comunista. Se codea con Rosalinde von Schirach, cantante de ópera y hermana del líder de las Juventudes Hitlerianas ${ }^{31}$, y con Leni von Riefenstahl, alias "Gletscherspalte" (grieta de glaciar, referencia a su supuesta frigidez), actriz e incipiente cineasta ${ }^{32}$.

28 Willy Münzenberg (1889-1940), diputado comunista y disidente de Stalin al igual que Maslow, fue además uno de los más eficaces publicistas del exilio. Entre 1933 y 1934 destapó las mentiras sobre el incendio del Reichstag en dos libros muy difundidos, con los que consiguió concienciar a la opinión internacional. Münzenberg hallaría un final tan misterioso como el de Maslow, ya que fue encontrado muerto en un bosque cerca de Saint Marcellin (Isère) con una cuerda atada alrededor del cuello. Nunca se supo si fue un suicidio o un asesinato perpetrado por fascistas o estalinistas.

29 Para la trayectoria de la prensa alemana en el exilio de París, vid. Maas (1981) y Peterson (1987).

${ }^{30}$ La verosimilitud de este episodio viene respaldada por estudios como el de Ford (2000) y las memorias de Rauschning (1942).

31 Baldur von Schirach (1907-1974) hizo obligatoria, en 1936, la pertenencia a las Juventudes Hitlerianas. Su hermana Rosalind fue cantante de ópera, conciertos y oratorios.

${ }^{32}$ Leni von Riefenstahl (1902-2003) actuó en películas mudas, rodadas en la alta montaña, como Die weiße Hölle vom Piz Palü (1929), de Arnold Fanck y G.W. Pabst, Der weiße Rausch (1931) y SOS Eisberg (1933), de Arnold Fanck, y dirigió y actuó en Das blaue Licht (1932). Fue sobre todo conocida por su eficaz labor propagandística al rodar Triumph des Willens (1934), sobre el Congreso del Partido de Núremberg, y, en 1938, el documental en dos partes Olympia sobre los Juegos Olímpicos, celebrados en 1936 en Berlín. 
La parte siguiente trata de la liquidación, ordenada por Hitler, de su anterior amigo Röhm, jefe de las SA, que le habían respaldado para que se hiciera con el poder. Esta matanza, que también se ha dado en llamar "Noche de los cuchillos largos", no fue más que una acción para afianzarse él mismo y a las SS en el poder exclusivo, aunque la acción se camufló de cruzada contra unos traidores. También quiso Hitler quitar de en medio a un grupo de allegados que se le habían vuelto incómodos por su homosexualidad manifiesta, pero que en el fondo obstaculizaban el camino de ascenso de las SS. Este episodio ha sido tratado en el cine por Luchino Visconti en su película La caída de los dioses. Llama sobremanera la atención la calidad casi cinematográfica con que este incidente se transmite en el capítulo de la novela de Maslow.

Las dos últimas partes del texto conducen al funesto desenlace, una vez atrapados los protagonistas: la condena y ejecución de la hija del general. Se esboza un descorazonador panorama del pantano espiritual en que ha caído Alemania, presa de una completa aniquilación de los derechos civiles. Maslow insinúa que el derrotero que va tomando el país lo conducirá a una absoluta catástrofe. Además, ya están anunciados en su esencia los diez años de negrura y maldad que aún le quedan a Alemania y a sus vecinos por vivir. Marianne, la hermana espía infiltrada, entretanto, se codea con un redactor exiliado en París; contacta, para silenciar su mala conciencia, con un activista comunista, y finalmente se pierde su pista en la campaña del referéndum del estado fronterizo del Sarre, que a consecuencia de esa consulta popular perdió su autonomía el 1 de marzo de 1935.

En suma, esta obra de Maslow carece acaso de una primerísima calidad literaria, pero aporta un testimonio de primera mano de alguien que participó en los inicios del desastre: los partidos de la izquierda, desunidos y resquebrajados, no supieron aprovechar el innegable respaldo popular que habían tenido en un momento dado para hacer frente al surgimiento del nazismo -el Partido Comunista Alemán, todavía en 1932, pudo sumar seis millones de votos; de unirlos a los del Partido Socialista, habrían alcanzado juntos una mayoría en el Reichstag.

Maslow sufrió en carne propia las consecuencias de esas políticas cegatas y, por ello, equivocadas que habían seguido los partidos democráticos al subestimar el peligro pardo que se cernía sobre el país. La hija del general deja un inestimable testimonio, personal y subjetivo, pero testimonio al fin y al cabo, de todo ello. Además, el autor insiste en que había sido su intención mostrar "en esa Alemania de los años en cuestión lo negativo, lo enfermizo, lo podrido y lo repugnante. Puesto que no pude ver nada positivo en ese país y en esa época, faltan los rasgos positivos". Y hace un resumen de las causas de esa evolución según las valoró en su momento:

[Los conspiradores] estaban aun menos decididos y no creían en ninguna causa en absoluto, mientras que Hitler al menos fingía creer en sí mismo, identificándose con su propia causa, y nunca entendió que esta "causa" no surtiera efecto porque la propagaba él, Hitler, sino porque se había convertido en portavoz de la incapacidad de los demás y del derrumbe de una causa, moribunda debido a su podredumbre interna y representada por dos grandes partidos que se llamaban partidos de los trabajadores. [...] En eso se parecían todos esos conspiradores, los oficiales al igual que los proletarios engañados y decepcionados: en que su conspiración 
era un espejismo fantástico, una fata morgana del desierto de ese marchito "sistema" alemán. Porque este, a pesar de las frases como latigazos de Hitler, seguía siendo exactamente lo que había sido antes: un capitalismo ahogado en la propia inmundicia, odiado incluso por los pardos, en el cual ya no creían ni siquiera los más inteligentes de los grandes capitalistas y contra el que se imaginaban poder rebelarse los pequeños aventureros neófitos, tan decaídos e indecisos, tan desarraigados y carentes de fondo, y al que se agarraban sin embargo como lapas a un cadáver ya descompuesto.

Acto seguido pronostica Maslow cómo continuará esa espiral de locura y violencia: "Antes de poder echar del poder a los nuevos usurpadores y demagogos, correrá aún mucha sangre". En retrospección, ciertamente resulta impactante una declaración tan convencida en un momento en el que muchos alemanes y gran parte del mundo estaban maravillados y atónitos por los "logros" y "avances" del Tercer Reich (pleno empleo, nuevo auge en industria e infraestructuras, organización social, etc.). A Maslow, los árboles sí le dejaron ver el bosque, y éste era profundo, oscuro y amenazador.

Mi edición de la novela ha consistido en documentar todo lo referente al fondo real. He intentado rastrear qué figuras auténticas se esconden bajo los diversos personajes en clave de la novela, algo que resulta cada vez más arduo a medida que nos alejamos, por la distancia en el tiempo, de los hechos históricos. He pretendido contrastar la diatriba y los cuadros satíricos del autor con lo que encerraban de auténtico y verídico. Con mi edición histórico-filológica espero ayudar a los lectores de hoy para que puedan comprender la alta ideologización que era la tónica general durante los años treinta, así como la ignorancia y la ligereza con que se puede poner en juego un endeble sistema democrático que, al fin y al cabo, se había conseguido tras un gran sacrificio en vidas humanas, en la Primera Guerra Mundial, y tras enardecidas luchas, desde las endebles instituciones democráticas, por incrementar los derechos civiles y mejorar las condiciones de vida de sus habitantes.

\section{BIBLIOGRAFÍA}

BETZ, Albrecht (1982): Hanns Eisler Political Musician. Cambridge: Cambridge University Press.

BEYERCHEN, Alan D. (1977): Scientists under Hitler. Politics and the Physics Community in the Third Reich. New Haven and London: Yale University Press.

CHARLE, Christophe (2004): Le siècle de la presse (1830-1939). Paris: Ëditions du Seuil.

CONARD, Pierre (1923): Trois figures. Falkenhayn, Hindenburg, Ludendorf. Paris: Flammarion.

CORNWELL, John (2003): Hitler's Scientists. Science, War and the Devil's Pact. New York: Viking Penguin.

CROSSMAN, Richard (ed.) (1949): The God that Failed. New York: Harper \& Brothers.

DEUTSCHER, Isaac (1969): Heretics and renegades, and other essays. London: Cape.

EVANS, Richard (1996): Rituals of Retribution. Capital Punishment in Germany 16001987. Oxford / New York: Oxford University Press.

FELDENKIRCHEN, Wilfried (1995): Siemens. Columbus: Ohio State University Press. 
FELDMAN, Gerald (2002): "Holocaust Assets and German Business History: Beginning or End?”. German Studies Review, XXV/I, pp. 23-34.

FISCHER, Ruth (1991): Stalin und der deutsche Kommunismus, 2 vols. Berlin: Dietz.

FORD, Roger (2000): Germany's Secret Weapons in World War II. Staplehurst: Spellmount Ldt.

GELIBTER, Giulio; y MELÉ, Carlo (1971): “El espionaje soviético". Revista de Estudios Internacionales, núm. 114, pp. 48-63.

GUÉROUT, Serge (1992): Science et politique sous le Troisième Reich. Paris: Ëditions Marketing.

HAYES, Peter (2004): From Cooperation to Complicity. Degussa in the Third Reich. Cambridge: Cambridge University Press.

HERF, Jeffrey (1984): Reactionary modernism. Technology, culture, and politics in Weimar and the Third Reich. Cambridge: Cambridge University Press.

$\mathrm{KOCH}$, Hansjoachim Wolfgang (1989): In the Name of the Volk: political justice in Hitler's Germany. London: LB Tauris.

KOCH, Stephen (1994): Double Lives. Spies and Writers in the Secret Soviet War of Ideas Against the West. New York / Toronto: The Free Press.

LÜBBE, Peter (ed.) (1990): Abtrünnig wider Willen. Aus Briefen und Manuskripten des Exils. München: Oldenbourg.

MAAS, Liselotte (1981): Handbuch der deutschen Exilpresse 1933-1945 Hg. Eberhard Lämmert. 4 Bde. München / Wien: Carl Hanser Verlag.

MADARIAGA, Salvador de (1974): Morning without noon. Memoirs. Westmead, Farnborough \& Hampshire: Saxon House.

MÜLLER, Ingo (1991): Hitler's Justice. The Courts of the Third Reich. Cambridge MA: Harvard University Press.

NEUFELD, Michael J. (2002): "Wernher von Braun, the SS, and Concentration Camp Labor: Questions of Moral, Political, and Criminal Responsibility". German Studies Review, XXV/I, pp. 57-78.

PETERSON, Walter (1987): The Berlin liberal press in exile: A history of the Pariser Tageblatt - Pariser Tageszeitung 1933-1940. Tübingen: Niemeyer.

RAUSCHNING, Hermann (1942): Makers of Destruction. Meetings and Talks in Revolutionary Germany. London: Eyre \& Spottiswoode.

RETZLAW, Karl (1971): Spartakus. Aufstieg und Niedergang. Erinnerungen eines Parteiarbeiters, Frankfurt / Main: Verlag Neue Kritik.

ROLFS, Richard W. (1996): The sorcerer's apprentice: the life of Franz von Papen. Lanham, New York \& London: University Press of America.

SIMPSON, Christopher (ed.) (2002): War Crimes of the Deutsche Bank and the Dresdner Bank. New York: Holmes \& Meier.

WIESEN, Jonathan (2001): West German Industry and the Challenge of the Nazi Past, 19451955. Chapel Hill / London: University of North Carolina Press. 